\title{
Memória e pertencimento: \\ a Vila Castelo Branco no espaço urbano de Campinas
}

Dissertaçāo de mestrado defendida no Departamento de Multimeios (Instituto de Artes - Unicamp) Orientadora: Profa. Dra. Olga R. M. von Simson

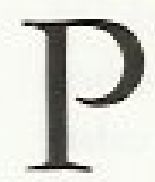

ertencer a uma cidade, vila ou bairro, näo é apenas viver nela, mas sim participar ativamente de seu cotidiano, de seus ritos e costumes. Podemos morar anos em uma determinada comunidade e nunca nos scntirmos realmente como pertencentes a ela. Mesmo que parte de nossa história pessoal tenha que ser contada utilizando os referenciais materiais desta localidade, isto não implica diretamente que nos sintamos parte desse lugar.

Construimos nosso sentido de pertencimento a partir de nossas lembranças, boas ou ruins, sendo necessário viver uma determinada experiência para podermos recordá-la, mesmo quando essa experiência é vivida de forma indireta como quando se lề um livro ou se ouve uma história. Quanto mais forte for o reconhecimento da sociedade em getal em relação à comunidade de pertencimento, tanto maior scrí a recorrència do individuo a estas lembranças para a composição de suas histórias de vida.

$O$ fato de privilegiar ou negar determina-
O passado conserva-se e, além de nào de forma bomogêrea 99
Bosi, Ecléa: 1994: 48 das lembranças ou períodos de nossa história de vida é comum. Este fato tornou-se marcante nos relatos dos pesquisadores do Centro de Memória-Unicamp, quando estes estudaram a memória de duas comunidades distintas de Campinas: 0 bairro Cambuí e a Vila Industrial. (SIMSON, 1997)

Em decorrência da trajetória pessoal dos moradores da Vila Industrial, a conquista da casa própria é considerada como uma melhoria de vida c a concretização de um sonho que os mantêm unidos e ligados à localidade até hoje, pois a ocupação e ordenação do bairro se fizeram de forma a permitir a reprodução das relaçōes de convivência existentes em seus locais de moradia de origem. Também os une a conquista de melhorias significativas para o bairro, através de movimentos internos (cscola, cinema, bares, igreja, praças e mercearias, entre outros) que permitiram a convivência intra-bairro entre iguais.

No bairro Cambui, por sua vez, os pesquisadores não foram tão bem recebidos como na Vila Industrial. Diferentemente do primeiro 
bairro proletário de Campinas, a população atual do Cambuí é formada por gente "nova" e os antigos moradores que ali permanecem não mais conservam o mesmo poderio económico de outrora. Pois, apesar de ainda o bairro Cambui ser considerado um espaço nobre em Campinas, ele não é mais o local de moradia para as familias de alto poder aquisitivo e de destaque na sociedade, que hoje preferem os condomínios fechados, criados na porção norte da cidade. Desta forma, o assumir-se como antigo morador do bairro não figura mais como um diferencial valorizado pela sociedade pequeno burguesa local. (SIMSON, 1997)

De forma análoga podemos extrapolar estas observações para a população da Vila Castelo Branco. Para os moradores deste conjunto habitacional encravado na porção sudoeste de Campinas, que ali permanecem e não experimentaram novas formas de ascensão social, o viver no bairro é tido como positivo e motivo de orgulho. Para outros, viver ou mesmo identificar-se como morador ou ex-morador da vila não é um processo fícil. Antes de negar, estes assumem suas origens, mas evitam comentar e mostram-se reticentes ao contato com o pesquisador que busca a memória desta comunidade c, por conseguinte, identificar seus integrantes às suas origens.

No processo de recompor as destinações dos espaços públicos de uma dada cidade $\mathrm{e}$ a interação/identificação de seus moradores com uma localidade especifica da teia urbana, faz-se necessário antes de tudo, um prévio reconhecimento das condiçōes que geraram esta organização social.

No caso da cidade de Campinas verificase que em seu início, o município teve seu ter- ritório organizado em função das condiçôes geográficas impostas pelo terreno. Os "Três Campinhos" cram as áreas mais propicias ao alojamento de animais e tropeiros (perto de fonte de água limpa, campo para pastagem c facilidade de locomoção dos animais) e por isso constituíram os embriōes para o surgimento da nova localidade. [1]

Postcriormente, com o inicio da urbanização, a ordenação dos espaços públicos passa a ser determinada pelas autoridades locais, e entäo as condiçòes geográficas perdem sua força $\mathrm{c}$ entra em cena a organização da população segundo seu poder aquisitivo. Os ricos recebem do governo municipal lotes no centro da cidade e de esquina, os trabalhadores pobres recebem pequenas propriedades agrícolas que são alocadas fora do perímetro urbano na porção sul da cidade. Esta configuração proporcionou uma valorização artificial dos terrenos de esquina que perdura até hoje. Mesmo que cstes possuam a mesma metragem dos de meio de quadra, os seus moradores atribuem um valor maior às casas ai localizadas.

"O arruamento para a construção das casas cra tarefa atribuída ao diretor do povoado, autoridade máxima do local que prolongava as ruas, matcava as quadras e dividia os terrenos, distribuindo-os a quem se dispusesse a contribuir, mediante auxilio, para as obras da matriz." (BADARÓ, 1996: 20)

As doações dos terrenos também eram consignadas à dimensão da construção que os novos moradores pretendiam erguer, para as 
maiores os de esquina, para as menores os terrenos de meio de quadra. Este fato é narrado por PUPO: "com o aumento do número de casas no povoado, surgiram as de menor frente, economizando terreno (...) os abastados faziam suas casas com duas salas de frente e corredor." (1969: 88)

Nesse processo de urbanização, que se dá concomitantemente à expansão da lavoura açucarcira e chegada das ferrovias à cidade, a instalaçâo dos bairros proletários de Campinas segue em direção sul preferencialmente, acompanhando o mesmo sentido de distribuição de terras para os agricultores pobres da ćpoca. Em seu início, essa orientaçio é dada pela baixa qualidade da terta para a agricultura, posteriormente, pela instalação de aparelhos públicos que causavam asco à população: forca, asilo de morféticos e variolosos, Matadouro Municipal c curtumes, além dos trilhos das ferrovias. Todas essas atividades foram alocadas ou transferidas para a regiāo da Vila Industrial, após os trilhos da Cia Paulista de Estradas de Ferro, juntamente com o alojamento para imigrantes e trabalhadores da ferrovia. Desta forma, podemos considerar a Vila Industrial como o primeiro bairro que assume sua característica fundante de vila para trabalhadores $\mathrm{em}$ Campinas [2]

Posteriormente, já na década de 60 do século passado, com a criaçāo do $\mathrm{BNH}$ c instalação da Cohab - Bandeirantes em Campinas, essa orientação rumo ao sul para o abrigo de bairros de trabalhadores é definitivamente estabelecida. A Cohab, seguindo a tendência geral, alocou preferencialmente seus conjuntos habitacionais para trabalhadores de baixa renda nesta região. Com a implantação das vilas Rica e Castelo Branco no último quartel da década de $60 \mathrm{c}$, posteriormen- te já na década de $80 / 90$, dos Distritos Industriais (DICs), este território é demarcado como área para construção de empreendimentos imobiliários destinados às classes populares. [3]

Nesse sentido, o historiador LAPA nos alerta:
"que a nova sociedade burguesa e ca- pitalista vem com o tempo impor regras de racionalizaçẫo do uso do espaço urbano, o que vem discrimi- nar de maneira mais acentuada as de- sigualdades nos niveis de renda e so- cial." (1996: 27)

Assim sendo, primeira parte do bairro São Bernardo (1954 - construida pela Fundação da Casa Popular) e posteriormente as vilas Rica (1966) e Castelo Branco (1967-1968) estão inseridas num processo de higienização do centro de Campinas. Elas foram construidas e destinadas preferencialmente para a transferència da população encortiçada e de baixa renda, antes moradora das regiồes nobres do municipia. Essa populaçio, originalmente habitava sub-moradias na região do Centro, Cambui e Taquaral. Este último bairro valorizou-se no final da década de 60 com a implantação de melhorias urbanisticas (Parque Portugal) e a remoçào da zona de prostituição para o Jardim Itatinga, criado também na porção sul da cidade para este fim especifico.

Contudo, a criação destas vilas populares nunca foi unanimidade em Campinas. O discurso oficial autoritário baseava-se no critério higienista, tanto no periodo em que a cidade foi assolada pela febre amarela, 1889-1900 (SANTOS FILHO, 1996), como no governo militar, 1964-1985. Já o discurso das elites, debatido nos 
jornais da época, pregava a miscigenação desta população de encortiçados e trabalhadores de baixa renda aos demais habitantes de bairros operários de formação mais antiga como forma de promover sua ascensão moral e intelectual.

Nesta visão, a criação destas megas vilas populares sem a devida miscigenação de classes trabalhadoras iria propiciar a instalaçào de "quistos sociais" impenetriveis, com valores éticos próprios devido à predominância de uma população específica, formando assim núcleos de marginalidade nocivos à estrutura social e política estabelecida (fig. 1). [4] Podemos encontrar paralelo no pensamento que orientou a distribuição da mão-de-obra necessária, mas não descjada, na época da escravatura. Durante o processo de importação e distribuição pelo território nacional, os negros sofriam o desmembramento de suas famílias e comunidades de origem, de forma a se cvitar a manutençāo dos laços afetivos e de identidade cultural, impedindo a formaçĩo de núcleos de resistência c possíveis focos que ameaçassem a ordem social vigente.

Esta mesma análise pode ser utilizada para observar as formas de distribuição da mão-deobra imigrante no final do século XVIII e início do seguinte. As companhias que regulavam a imigração distribuíam os trabalhadores pelos estados brasileiros de forma a dificultar a formação de grandes comunidades de uma única nacionalidade, favorecendo assim a convivência entre estrangeiros diversos e brasileiros natos, com o intuito de preservar a integridade nacional, além de promover um desejado branqueamento da população de trabalhadores brasileiros menos qualificados.

Essa visão que defendia a integração de diferentes comunidades como forma de elevação moral de uma pelo contato com a outra mais confiável e, por conseguinte, a rejeiçāo de grandes concentraçōes de pessoas de uma mesma origem, penetrou, de uma forma ou de outra, toda a sociedade campineira da época. Mesmo os trabalhadores que se transferiram para essas localidades levaram consigo este estigma, o que dificultou, de certa forma, a formação de uma identidade local baseando-se no orgulho de pertencer ao bairro.

Devido aos avanços e retrocessos da industrialização e implementação da comunicação de massa, cria-sc então a figura do 'morador espectador', que se relaciona com a cidade e não com o bairro, está sempre a procura de novas oportunidades de ascensão social. Esta postura dificulta ou até mesmo impede a criação da identidade lo$\mathrm{cal}$, pois a criação desta passa obrigatoriamente pelo envolvimento com a comunidade $\mathrm{cm}$ que reside-Desta forma, este morador espectador não está preocupado com a preservação da memória local e até mesmo a nega quando the ć interessante. De forma análoga temos o processo de inserção do negro na sociedade brasileira. Desde o periodo regencial, o negro, que de certa forma ascende socialmente, scja pela vertente cultural (música, literatura, teatro, etc.) seja pelo econômi$\mathrm{co}$, tende a negar suas origens $\mathrm{e}$ a própria sociedade ameaça a negar-lhe sua raça, branqueando-o quando the convém. Como exemplo podemos citar o caso do compositor e maestro campineiro Carlos Gomes, que tem o seu tom de pele "clareado" pelos pintores ao longo do tempo, proporcionalmente ao aumento de sua fama.

Contribuindo nesse processo de esquecimento das identidades de comunidades populares, as instituições oficiais, na maioria das vezes, voltam-se para o registro da trajetória das 
- CORREIO pOPULAR - 5. Feira, 3 de Outubro de 1968

\section{Em Campinas iá estão habiładas a Vila Rica e a Vila Castelo Branco.} Euase concluida se, encontra a Vila Boa Vista. Em construçäo, as Vilas Costa e Silva, 31 de Marco e do Plano do Terreno Prúzrio. Säo etapos irentes do Plano Habitacional do Govèrno, financiado pelo $\mathrm{BNH}$, sigla que ficou famosa neste_Brasil de três qnos para cá. Há quem acredite que, ao invés de resolver, o Plano Habitacional veio agravar. os nossos problemas sociais. Em pesquiso, ○ "Correio Popular" levantou gsp diferentes angulos da questáo. Os depoimentos colhidos permitem avaliar, neggțitas ou afirmofivamente, os

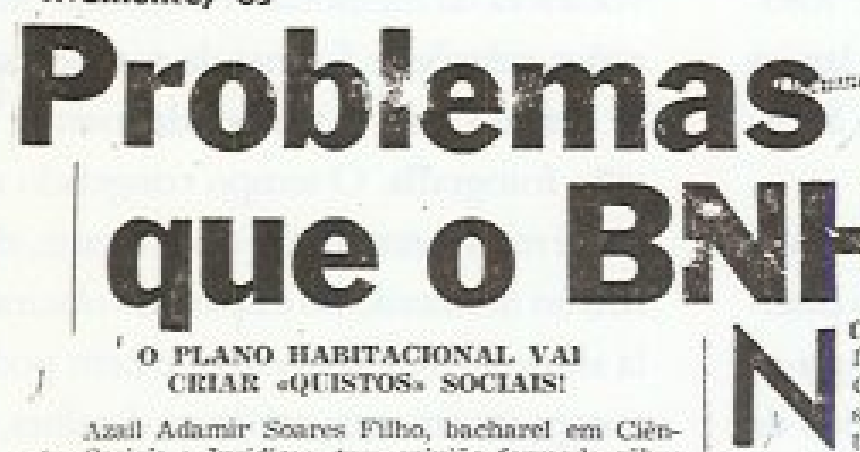

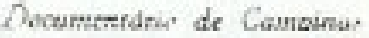

as Sociais e Juriflicas, tem opiniajo formada scóbre o assuntoc

-O Plano Habitacional nesolve em parte o powbiema habitacional e, concomitantemente, cria prohirmes novos de solnesio tho diffed quanto aos pncexistentes, antes da excecusio do Plano. Contudo, os problemas criados sảo de natureza cutra . A principal objecilo a exuecucio do Plano Habitacio rat é a criacho, em futuro multo próximo, de squis. toe socisis. Os aglomerados bumanos que se formam, sem planejameato cientifioo. Gentro de muito poseo tempo formarắ ảreas impenetriveis acs hahitantes do prógujo bairro em que as casas populares estăo situatias. Serio formados nacleos de vivencia próncia, com baixo nivel social e sem * mesela nocersairia, seja de profissóes, seja de posigies socials oa rxesmo simples nivel culturnl.

Repetir-se-60 o fenomerso es problemas fit werifleados no passadio, por exemplo, em Santa Catadits, com a colónia alemấ que lí se instalou.

Poder-se-ia objetar que dentro do própro planejemento existe saskitiricla socinl ou orglins encarregados de observar e nesolver o peoblema. Entendemsos, no entamio, que para uma solucho pelo menos satisfatórik, nocessurto se tornaria um gran d. nimero de pessoss altamente especinlizado c, por tanto, sumamente oneroso acs cofres püblicas. Dal porque vishambramns que, muito bnevemente, estarlio formablos múclecs populacionsais de nivel cultural extremamente baixo e completamente as armpio de qualquer interpenetraclio dos aglomera. dos virinhos e que constituem as beirras noemais.

Serin melhor que o Banco Nacional de Habitacio construisse, atraves de seus firanciamentos, triciros multo pequenos (10 ou 20 casas) jil intezrabos nos bairnos di periferiss. ram que eks estâ ajudando a resolver o problema habilacional do powo betasileiro. Outros, acham que ẻles solucionam èsec problema, mass em parte, criando paralelamerite grawes ameacas à tranqullidade e a sezuranes da popslacio.

O fato é que, em saa fase apenas iaicial, o Pfa. no Hahitacional instauracio jelo Ciow'rno, em sua ênsia de corrigir uma situaçio, onde a maforia do povo morava em easess alupartas debaixo de prestagües extorsivas, sofrect a incistîncia de fallas. Uma delas e que foram retanidos em determiradios nuclens, lisgieamente, individues de ma indole, for mardo eomunidades de alto indice criminal, apenas porytue tais elementos se encontravam em camaly de baixo padrấo exonimica, fustamente as com? pladas pelo Plano linbitacional. Sem um efi. rio scletivo, hoxive em direcio aos peimeiros hucleas formadas, uma canalisacio de familias potpto sem cultura, exjos integrantes de sexo mascul f l nham delingulindo ou estavam propicip of chansgredir a Jei, ma primeira oportunidadc 1 itho merot de sult escassez de recurses econórfic ?le sua

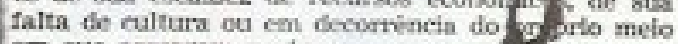
em que passerem a viver.

A fim de esclakver a oginifio pat 1 sobre as cbjecóes Jevantadas ao Plano Habitac Sal, quatro personalidades foram ethimadas a opirstr. O ponto de vista de cacta ums delas está contido nesta neportagem. A pergunta que cada uma fot corvinia. da a responder é: 0 Plano Habitacjoral conforme toi idealizado pelo Govirno e vem sendo desenvolvido, resolve ou agrava on problemas sociais do pals? $x$.

Fig. 1 - Mesmo antes destes debates ganharem as páginas dos jornais, seus efeitos já eram sentidos na pele pelos moradores das vilas populares de Campinas. Esta visāo negativa sobre as vilas populares também foi encontrada nos depoimentos colhidos dos moradores da Vila Castelo Branco no decorrer da pesquisa. Porém sempre de forma a demonstrar que estas pessoas estavam erradas e que viviam em melhor situaçāo que aqueles que não aceitaram morar nas vilas populares na época. 
classes dominantes e o que fica registrado e é divulgado via museus, bibliotecas, centros culturais e centros de memória são os fatos ligados a este extrato social. A preservação c divulgação da memória dos extratos populares dependem da iniciativa de seus próprios membros, o que geralmente só ocorre em situaçōes de conflito social ou devido ao trabalho pioneiro de pesquisadores que, valendo-se da metodologia da História Oral aliada à análise fotográfica histórica, reconstroem a saga de largos contingentes populacionais incorporados à formação dos centros urbanos. [5]

Esta constataçāo pode ser feita quando buscamos conhecer a memória da Vila Castelo Branco. A memória preservada até entäo restringia-se aos recortes de jornais da época e relatórios da Cohab Campinas, que retratam a visão das clites sobre o processo de formação desse conjunto habitacional (memória oficial), sem, contudo, registrar a memória real de seus moradores. Procurando reverter essa orientação, instituiçōes como o Centro de Memória da Unicamp vêm implantando c incentivando linhas de pesquisa no sentido de reconstruçĩo da história das cidades sob a ótica das populaçōes que costumeiramente não encontram espaço para registrar suas trajetórias $\mathrm{c}$ visão de mundo.

Nesse processo de reconstrução da memória da Vila Castelo Branco, empregamos as técnicas da história oral aliadas à fotografia como provocadora da memória. A memória preserva situações, relaçõ̀es $\mathrm{c}$ formas de comportamento que se alteram com o tempo, da mesma forma que uma fotografia. O tempo congelado na imagem não é mais o retrato fiel do presente, ele já se perdeu no momento do disparo do obturador. Aquela situação não mais existe e nem poderá ser recomposta em seus mínimos detalhes, contudo a memória, ao observar uma fotografia, acródita que está vendo o presente, que pode seguir daquele ponto $\mathrm{em}$ diante sem que nada tenha mudado.

No processo de interação com a comunidade e resgate das fotografias das caixas de sapa-

Foto 1 - Nelson Camargo (o terceiro ciclista, da direita para a esquerda), durante passeio de bicicleta com os amigos até Bom Jesus de Pirapora.

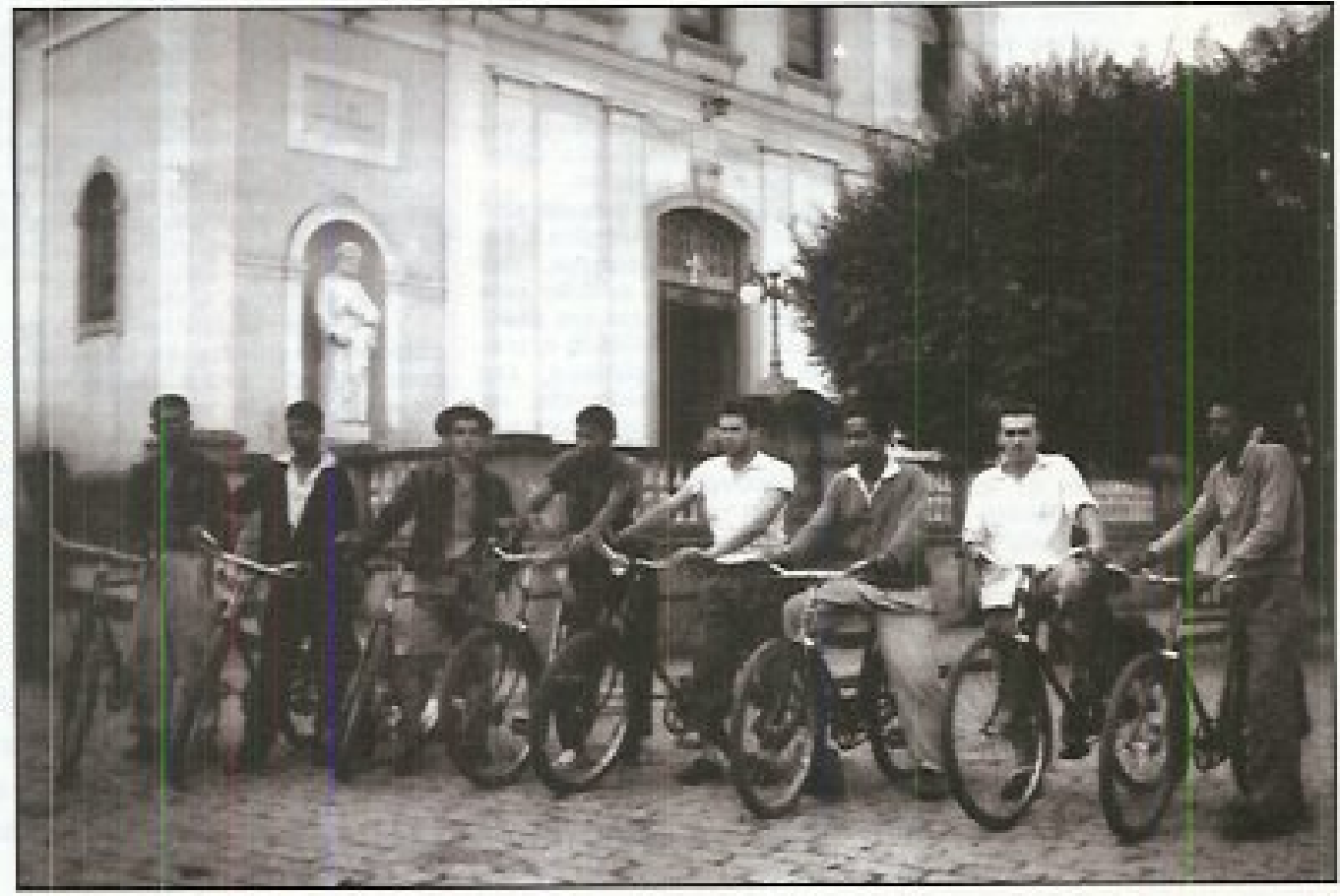


tos e fundo de gavetas, dentre as imagens recolhidas, verificou-se a predominância das relacionadas ao trabalho ou "aventuras" extra-bairro no grupo masculino (fotos $1,2 e 3$ ), enquanto as imagens da família $\mathrm{e}$ intra-bairro provinham dos acervos femininos (fotos 4 e 5), aspecto já discutido com muita propriedade por pesquisadoras como LEITE (1993), BOSI (1998) e QUEIROZ

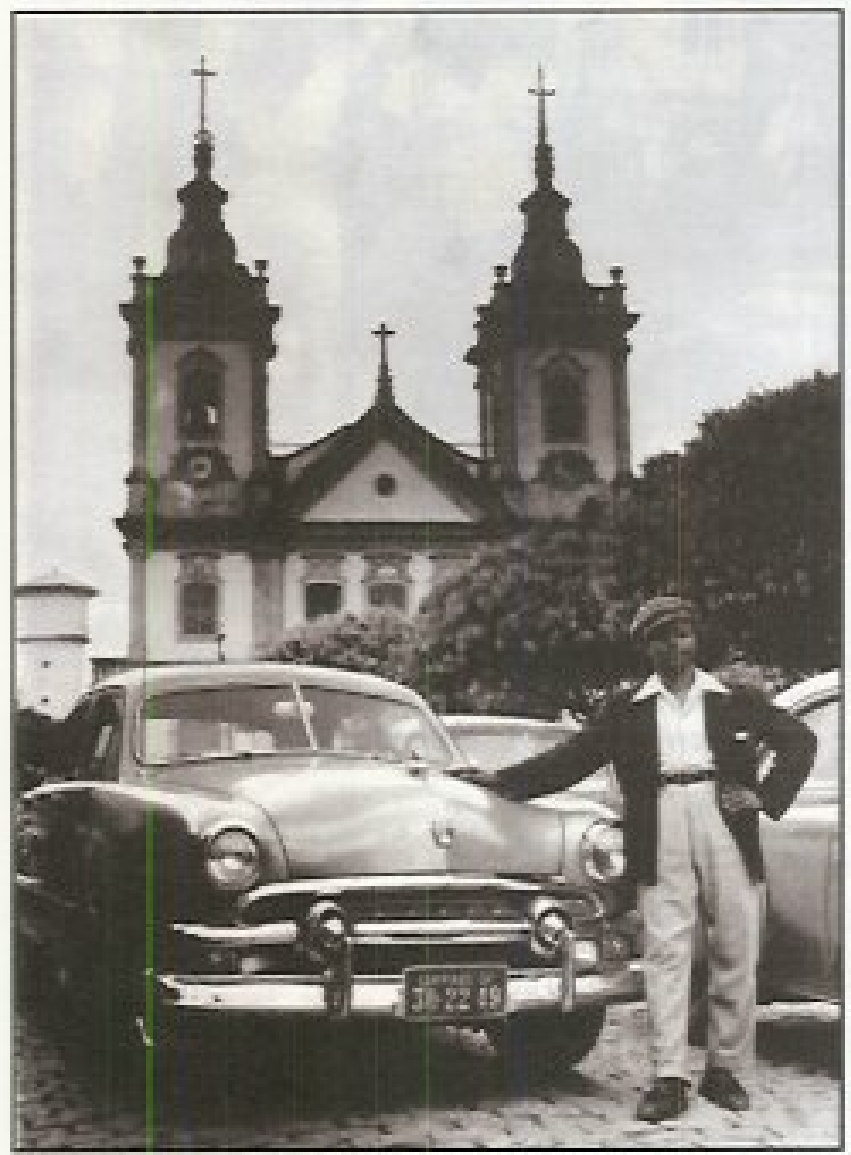

Foto 2 - Além das imagens das próprias aventuras, os informantes masculinos também selecionavam os instantâneos de seus pais e avós em situaçōes distantes do lar e da familia. Na fotografia acima, vê-se o avô de Nelson Camargo com seu "carro de praça" em viagem a Aparecida-SP.

(1991), entre outros de igual importância.

Em um segundo momento, quando passamos a registrar as falas dos informantes, notou-se uma diferenciaçāo entre o elaborado pelo grupo de maior escolaridade e o que tem na

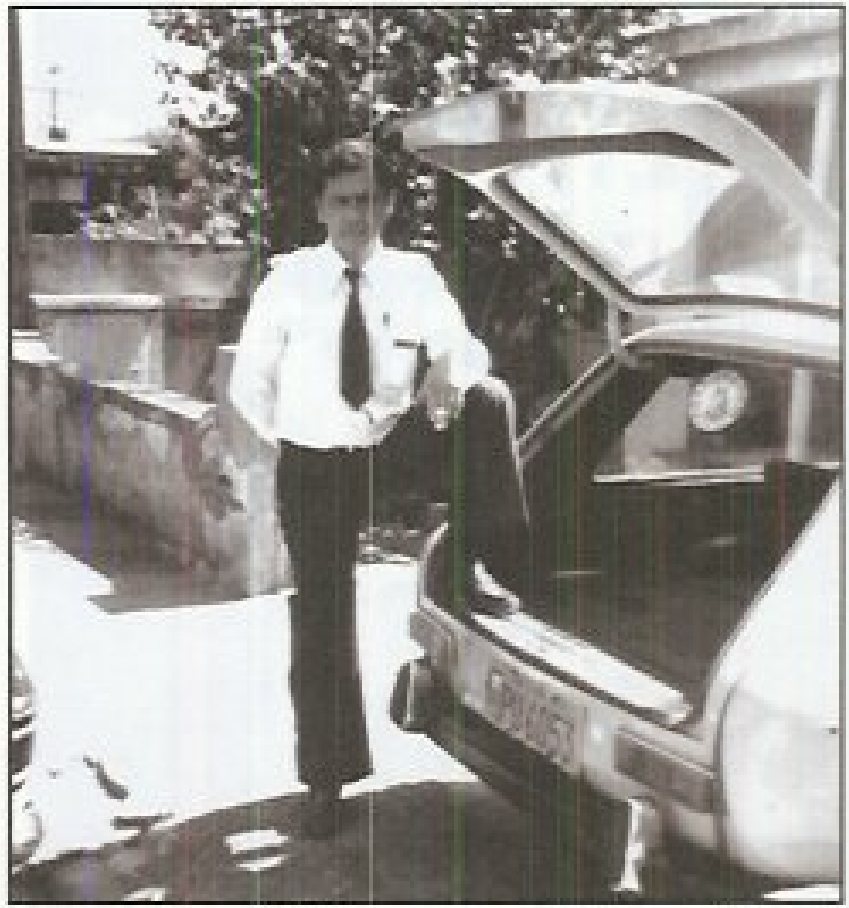

Foto 3 - Nelson Ribeiro apresentou fotografia que mostra o carro recém adquirido com o salário de motorista de ônibus. Ao fundo vê-se o muro de sua casa na Vila Castelo Branco.

vivência do dia-a-dia a construção de seus referenciais. Um exemplo contundente encontramos na fala de Nelson Ribeiro, 40 anos, $2^{\circ}$ grau completo. Este, ao narrar os acontecimentos pertinentes à Vila Castelo Branco e sua trajetória pessoal, o faz relacionando e analisando os fatos e seus desdobramentos na comunidade. Por outro lado, Maria Cândido, 73 anos, semi-alfabetizada, narra os acontecimentos recompondo os diálogos sem, contudo, tecer relaçōes mais fortes com as implicações sociais destes. Para ela, bem como para outros informantes de baixa escolaridade, as conquistas pessoais estäo relacionadas diretamente a um plano superior, seu esforço pessoal vem a coroar a vontade divina, a vontade de Deus. Onde a análise da conjuntura social é sublimada, as questồes que se referem à discriminação não são analisadas ou sequer tocadas durante as conver- 


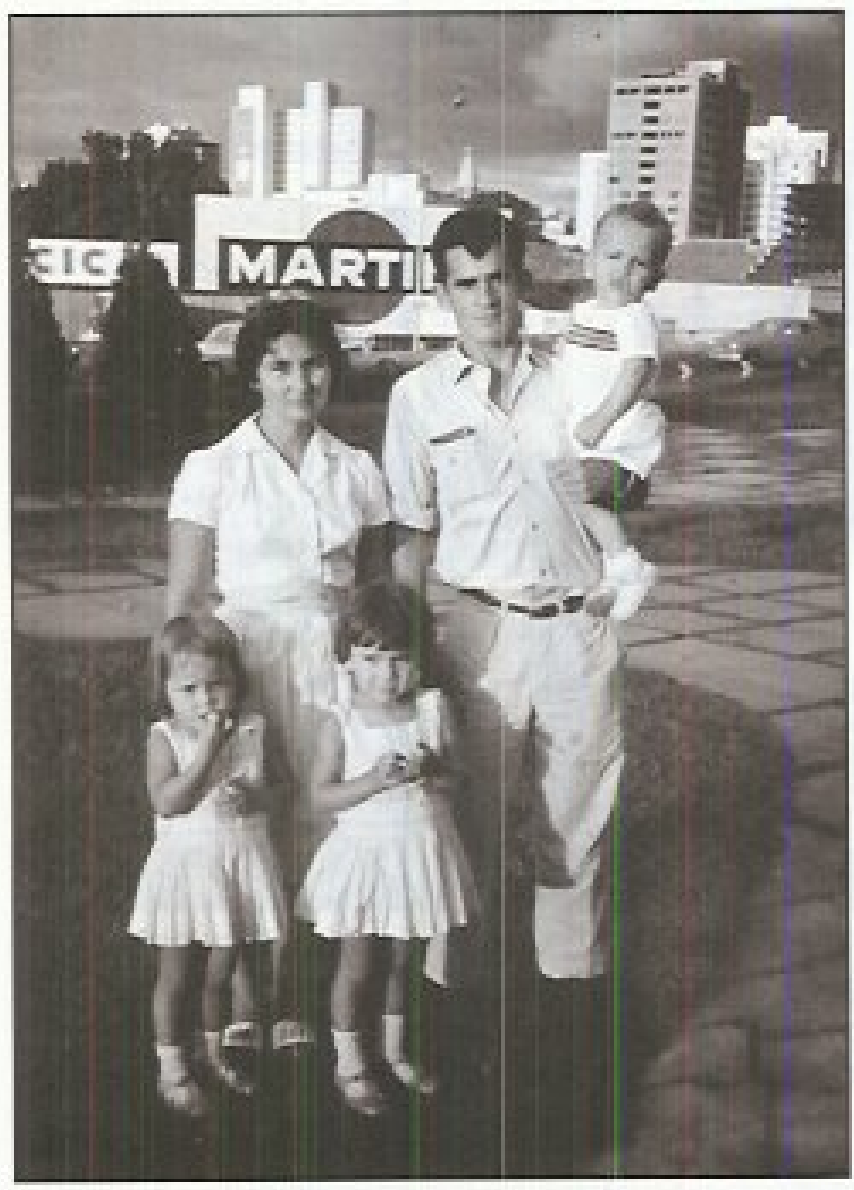

Foto 4 - Nas imagens selecionadas por Nilza Ribeiro, a familia estava representada.

sas. Contudo percebe-se no nâo dito que elas não são ignoradas, mas sim não-faladas para se evitar o confronto com a sociedade e com a própria realidade.

Por fim, verificamos que, devido ao emprego de fotografias no processo de recomposição da memória, a identificaçäo de passagens que demonstram esse conflito foi facilitada. No discorrer dos relatos, muitas vezes os informantes mergulhavam de tal mancira nas fotografias que deixavam escapar observaçōes que de outra forma não surginiam. Quando se davam conta destes deslizes, apressavam-se a corrigir as informaçôes ou mudavam drasticamente de assunto, selecionando outra imagem menos perigosa.

É importante observar que a memónia de

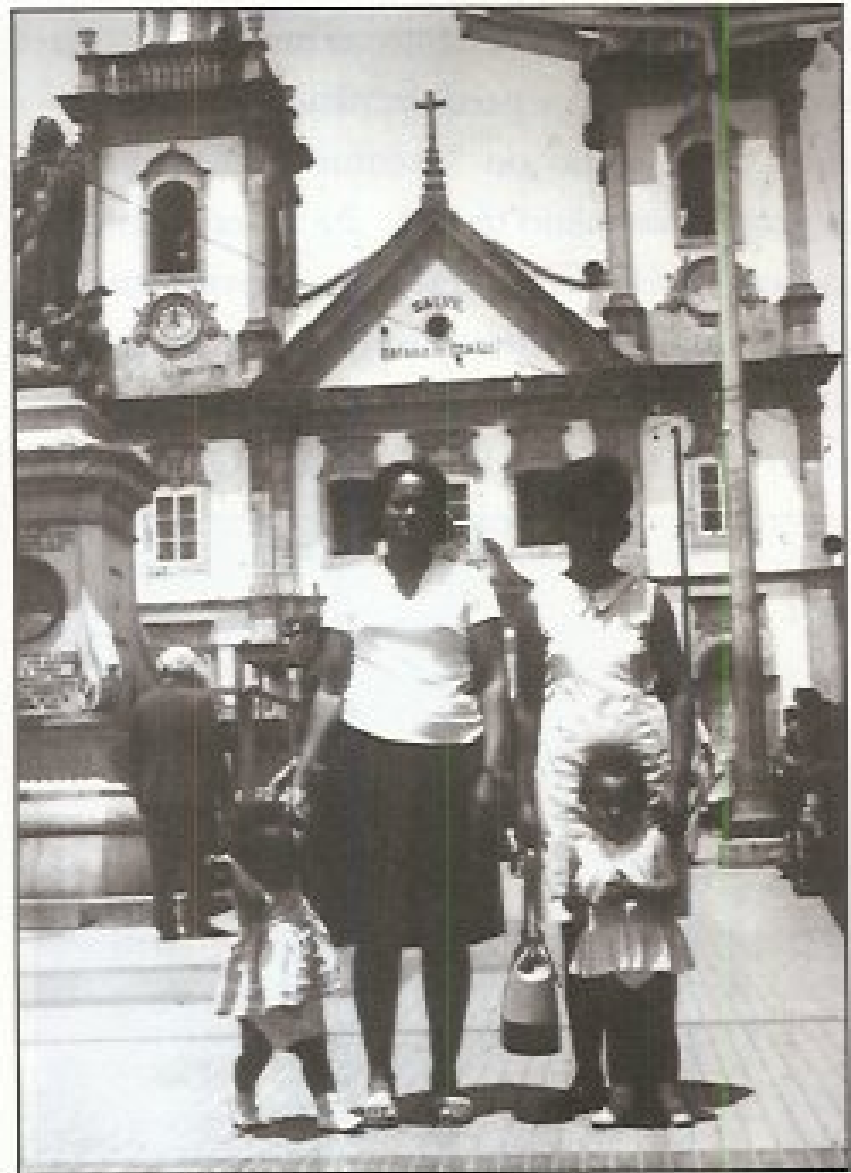

Foto 5 - Maria Candido (à direita), e a filha em visita a Aparecida-SP.

uma entrevista de história de vida não é a mesma coisa que uma conversa informal com amigos ou mesmo que uma entrevista jornalística. Neste sentido, ver é então produzir sentido, é também fazer história. Ver e falar, falar e ouvir. Não é só o entrevistador que ouve, não é só o entrevistado que fala. Não é um monólogo. É um diálogo, mesmo que este seja entre desiguais. [6]

Ouvir significa uma disponibilidade que entra em conflito com o que poderia vir a ser uma invasāo, a utilização do outro que abre sua vida, sua intimidade, sua história. Entretanto este fazer história pode ser compreendido como interação; trata-se efetivamente de uma interaçāo ou uma ação entre os cúmplices envolvidos no processo da entrevista. Há uma troca de "sabe- 
res", tornada possivel pela utilização da História Oral, que lida com informaçòes que estão vivas.

O momento da entrevista tem um sentido próprio, distinto do uso que se possa fazer do produto-entrevista, mas que é perseguido na transcrição, na releitura e na versão final da entrevista, quando se torna arquivo oral e escrito. A experiência recente da História Oral fez redescobrir o sentido próprio da entrevista não como fonte para um produto posterior e final da pesquisa, mas como momento fundante, onde não só se recolhe a história, mas também se vive a memória e cria-se um acontecimento que também faz história.

Nesse processo de falar e ouvir atuam mecanismos extremamente sutis que estão relacionados com a construção da identidade pessoal. Memória e identidade estão intimamente ligadas. Não podemos esquecer que, nesta sociedade complexa, cada pessoa pertence a diversos grupos e cada grupo propôe um modelo de identidade, sendo que cada grupo tem suas exigências e suas expectativas.

Desta forma urge empregarmos metodologias que permitam reunir estes fragmentos de forma a tentar construir uma versāo mais completa dos acontecimentos. A História Oral e de Vida, aliadas à fotografia, constituem-se em ferramentas importantes nesse processo de reconstrução do passado sob um olhar do presente.

\section{NoTAS}

1 - Os "Trés Campinhos" ou Campinas que deram origem ao Municipio de Campinas, segundo Celso Maria de Mello Pupo, localizavam-se na baixada da atual av. Moraes
Sales, na Praça Carlos Gomes, sendo este o maior deles e por último, na confluência das av. Brasil com Orizimbo Maia. Para maiores detalhes ver: PUPO, Celso M. de Mello. Campinas set Berpo sua Junentude. Campinas: Publicações da Academia Campinense de Letras, $1969 . \mathrm{n}^{2} 20$

2 - Podemos identificar pelos mapas de Campinas que os bairros menos valorizados encontram-se localizados ao longo dos trilhos da ferrovia e forra do rocio original. Contudo, a região onde se localiza a Vila Industrial foi a que mais se desenvolveu nesse periodo, atraindo para si a preferència dos investidores locais no que tange à construçāo de moradias para trabalhadores de baixa renda. Podemos encontrar referência a estes fatos nos trabalhos de PUPO (1969), LAPA (1996), BADARÓ (1996), entre tantos outros pesquisadores da história de Campinas.

3 - Dos conjuntos habitacionais criados pela Cohab em Campinas, apenas a Vila Costa e Silva, 31 de Março, Vila Santana em Sousas c Miguel Vicente Cury foram construidas distantes do eixo principal da ferrovia em sua porção norte. Os demais estão localizados além ferrovia do lado sul. O trilho da Ferrovia Paulista configura a primeira grande divisão entre norte e sul da cidade, entre centro e periferia, conforme dados disponíveis no Plano Diretor de Campinas de 1991.

4 - A discussão dos problemas sociais que a construção de vilas populares em Campinas poderiam gerar foi levantada não só nos círculos mais fechados da sociedade Campineira; este debate chegou aos jornais da época, como no Carreio Popular (03/08/1968), retornando por ocasião da construção de cada nova vila popular. Também pelos moradores destes conjuntos habitacionais durante a pesquisa de mestrado que gerou 
este trabalho.

5 - Conceitos desenvolvidos no artigo de SIMSON. "Memória e poder na sociedade do esquecimento. O exemplo do Centro de Memória da Unicamp." In: Arquitus, Fontes e Noses Temobogias: Questōes pana a História da Educaçao/Luciano Mendes de Faria Filho (org.). Campinas, SP: Autores Associados; Bragança Paulista, SP: Universidade São Francisco, 2000. (Coleção Memória da Educação)

6 - Temática abordada no livro de SIM$\mathrm{SON}$, Olga Rodrigues de Moraes von. (org.) Os Desafos Contentpanuneos da Histónia Onal - 1996. Campinas: CMU-Unicamp, 1997.

\section{BIBLIOGRAFIA}

BADARÓ, Ricardo de Souza Campos. Campinas, o Despontar da Madernidade. Campinas: CMUUnicamp, 1996.

BOSI, Ecléa. Memóna e Saciedade: L mbrangas de VeHoos. $3^{2}$ ed. São Paulo: Companhia das Letras, 1998.

Dianio do Pove, Correio Poptlar. Canprinas Século XX: 100 Anos de Históna. Campinas: Rede Anhanguera de Comunicação, 2000.

LAPA, José Roberto do Amaral. A Cidade: $O s$ Cantos e os Antras: Campinas 1850-1900. São Paulo: Edusp, 1996.
LEITE, Miriam L. Moreira. Retratas de Fundila: LeiIura da Fotografá Histónica. São Paulo: Edusp, 1993. PUPO, Celso Maria de Mello. Campinas, sen Bențo e Jnventude. Campinas: Publicaçòes da Academia Campineira de Letras, 1969. n² 20

QUEIROZ, Maria Izaura Pereira de. Varieģies Solme a Técrica de Gravador no Registro da Informațio V Vura. São Paulo: T. A. Queiroz, 1991.

SANTOS FILHO, Lycurgo de Castro; NOVAES, José Nogucira. A Fứre Amareke em Canquinas: 1889. 1900. Campinas: CMU-Unicamp, 1996.

SIMSON, Olga Rodrigues de Moraes von. Depasmento Onale Fotograffa na Reronstrução da Memónia Histónio Soxiabogica: Reflexōes de pesquisas Boldtim do Centro de Mensória-Unticamp. Campinas: DGA-6 Unicamp, vol. 3, n² 5 jan/jun 1991.p. 14-24. (Org.) Os Desaffor Contemporaneos da Históra Hral 1996. Campinas: CMU-Unicamp, 1997.

- "Da 'bastilha negra' à proletarização: Bairro, identidade e memória de espaços negros de Campinas." Campinas: Centro de Memória-Unicamp. 1999. Relatório de pesquisa, processo $\mathrm{CNPq}$ nr. 522322/94-8 (RE). Campinas CMU. 